\title{
An Overview of Manufacturing Knowledge Sharing in the
}

\section{Product Development Process}

\author{
James Gao* \\ Faculty of Engineering and Science \\ University of Greenwich, Chatham Maritime, Kent, ME4 4TB, UK \\ Email:j.gao@greenwich.ac.uk \\ and A Y C Nee \\ Department of Mechanical Engineering \\ National University of Singapore, 9 Engineering Drive 1, Singapore 117576 \\ Email: mpeneeyc@nus.edu.sg
}

\begin{abstract}
This paper provides an overview of reported research relevant to the management of manufacturing related knowledge and highlights the sharing of knowledge in the product development process. Previous research and concepts reported by international researchers and examples of the research projects carried out by the authors' research teams will also be introduced. Publications reviewed are in the scope of information, communication and knowledge management technologies in product development and manufacturing. Some key concepts and issues in knowledge management are introduced first, as a foundation for the remainder of the review. The different approaches to knowledge management and knowledge sharing, and the different types of knowledge and key issues in the product development process are discussed. Then manufacturing knowledge and its application in the product development is reviewed. The focus is given to the discussion of the approaches to sharing manufacturing knowledge relating to the product development process and indicating the future challenges and research directions.
\end{abstract}

Keywords : Knowledge Management; Knowledge Sharing; Manufacturing Knowledge; Product Development; Information and Communication Technologies

\section{Theoretical Definitions of Knowledge}

Knowledge Management as a subject of study and practice arose as a consequence of the Knowledge Economy. The value of the organisation lies not only within the product and service that it provides, but within its knowledge asset. ${ }^{1}$ This has become increasingly important during the birth of the digital age and the internet. ${ }^{2,3}$ The definition of knowledge depends on how it is categorised and can consequently affect the way in 
which it can be used. ${ }^{4}$ A typical definition given by Young et $\mathrm{al}^{5}$ stated: Data is text or numbers. Information is data with added context to explain the data. Knowledge is the interpretation of information in order to assign meaning. In this definition, knowledge can be organised into blocks which can be coded, shared and used. Consequently, this definition has originated from and is mostly used for managing knowledge by information systems.

Polanyi ${ }^{6}$ classified Knowledge into tacit and explicit. Explicit knowledge can be articulated and represented in formal languages (codified), and can be shared between different systems without losing its integrity. Tacit knowledge is rooted in people's personal experience and beliefs, and is more difficult to express, codify and therefore share. Polanyi's concept was adopted in Nonaka's research, in which knowledge was seen as residing in and originating from individual employees, which together forms the collective knowledge of the organisation. ${ }^{7}$ Explicit knowledge may be captured and represented in a database, while the data itself needs to be interpreted and understood within the context of the organisation (tacit knowledge) so that it may be effectively used.

In a more pragmatic approach, knowledge was defined in terms of its source and its application, and is categorised as being declarative, procedural or causal. ${ }^{8}$ Declarative knowledge (or know-what) is the content of knowledge. Procedural knowledge (or know-how) refers to the processes of using knowledge. Causal knowledge (or know-why) refers to the underlying recognition of where it is appropriate to apply knowledge. Hicks et $\mathrm{al}^{9}$ pointed out that other components such as behaviour aspects and organisational learning are missing from the data-information-knowledge hierarchy. They presented an alternative definition, referred to as Explicit Islands in a Tacit Sea, in which the sea of tacit knowledge enables the creation of data, information and explicit knowledge, and the selection of the tools for best practice.

Bohn ${ }^{10}$ defined technological knowledge as the knowledge associated in realising products and services, and recognised its tacit and explicit elements. A third dimension, i.e., knowledge maturity was introduced. A scale of knowledge maturity was proposed in which knowledge types are used to describe the maturity of a process. Process maturity is defined as the ability to which its attributes can be codified and standardised. Bohn took a pragmatic view of industry, claiming that any organisation will have a mix of processes at varying levels of knowledge maturity, which will in turn affect learning, problem solving, operation and job roles. Mountney and $\mathrm{Gao}^{11}$ also recognised the need to incorporate knowledge about the development of new manufacturing processes which were categorised as immature (because their capabilities cannot be codified) and was referred to as innovative manufacturing knowledge in their research. 


\section{The Shared Context for Knowledge Management}

As described above, knowledge has been interpreted in several ways, and some commonalities exist between various definitions, e.g., all definitions indicated a codifiable perspective to knowledge where it is easy to articulate in a shared context - a common emerging theme of sharing information. Alavi and Leidner ${ }^{1}$ stressed that a knowledge management system must be able to capture individuals' knowledge yet assign meaning which is relevant for specific applications. The need for the shared context governs the appropriate knowledge type. They supported the use of both tacit and explicit knowledge as they are mutually dependent and reinforce each other.

Zack $^{8}$ stressed that tacit knowledge should be made explicit because it is only then that knowledge can be a competitive advantage. Fahey and Prusak ${ }^{12}$ saw tacit knowledge as being fundamental to the creation and use of explicit knowledge. Tuomi ${ }^{13}$ proposed ways in which tacit and explicit knowledge could be exploited for different purposes. The strength in explicit knowledge would be in articulating and codifying routine operations in a shared context.

What emerges from previous research is how the definition of knowledge governs the way in which it can be represented and managed. As described by McMahon et al, ${ }^{14}$ two main approaches have been adopted in knowledge management: The first is concerned with codifiable knowledge and the development of a mainly information system perspective in supporting this. The second is a more social perspective evident, or a community approach, where knowledge is not so easy to articulate and a shared context needs to be established in addition to the knowledge.

Saunders et $\mathrm{al}^{15}$ reported the findings of an exploratory industrial investigation to evaluate the challenges encountered through a case study within a multi-national automotive manufacturing company. They commented that there remains a continued focus on further reducing the number of unique new product development programs, yet simultaneously increasing the number of worldwide product launches and maximizing global presence, especially in the emerging growth markets. This has been facilitated by reducing the overall development and test costs by maximising on shared common global programs, i.e., global vehicle platforms, coupled with the realignment of the respective worldwide manufacturing and product development organisations. The authors believed that the Socio-Technical dimension within the auto-industry has become increasingly more complex and unmanageable. Therefore, globally dispersed engineering teams that rely on the close integration of a network of external specialist external suppliers, across multiple time-zones, to leverage design and manufacturing expertise will benefit from further research in this domain. 
Giddaluru et $\mathrm{al}^{16}$ carried out research on establishing a shared product model for the integration of product lifecycle applications. They proposed a modular product structure methodology and demonstrated its advantages in the implementation of product lifecycle systems in the collaborative company. The proposed methodology gives guarantee for manageability, integrity, consistency, security, and traceability of product data in the whole lifecycle, and various dynamic data information can be shared in the product evolution chain. A mapping process of product data between computer aided design (CAD), product lifecycle management (PLM) and enterprise resource planning (ERP) systems was developed which gives seamless flow of information between them, Giddaluru et al. ${ }^{17}$ Because multi-national manufacturing enterprises are evolved for many years and there is a large amount of previous product development and manufacturing information, they are also developing tools for the migration of legacy data to the new structure using a PLM system.

\section{Knowledge Management Issues in Product Development}

The above theories of knowledge are applicable to the product development process. Hicks et al ${ }^{17}$ referred to the product development process as an information transformation process, in which the decisions necessary to move a design from one state to the next are driven by knowledge and information. The need for explicit knowledge and the importance of representing it in an information framework was explored. Information was interpreted as being either formal or informal. Formal information is structured and can be represented. Informal information is less structured and usually obtained from discussions. Knowledge is inferred from information, the preference being towards informal information. Because of its less structured and personalised nature, informal knowledge is seen as being possibly unreliable due to bias. An example of the use of the declarativeprocedural-causal approach to knowledge can be seen in research by Fu et al, ${ }^{19}$ who investigated the knowledge content required for design in the aerospace industry. The results of their research were high-level and knowledge was categorised into market, human, technology and procedural.

Previous research demonstrated that in product development, knowledge content and form are inextricably linked. McMahon, et $\mathrm{al}^{14}$ demonstrated how the knowledge form can influence the type of support system used. They discussed the personalisation (tacit) and codification (explicit) of knowledge, linking this with the community and information-system approaches to knowledge management. The product type itself is also a major influence on the selection of the approaches. The information-system approach, which promotes the capture, use and re-use of knowledge, is advantageous for standardised, mass-produced products, whilst the community approach is suited to customised products. However, the need for both approaches is acknowledged in the product development process. 
Other researchers have also considered the tacit and explicit components of knowledge, for example when analysing the product development of automotive products. ${ }^{20}$ The tacit nature of manufacturing in particular was also highlighted by Grant and Gregory, ${ }^{21}$ because it requires a wide range of knowledge from different people. Wong and Radcliffe ${ }^{22}$ investigated tacit and explicit knowledge used in the design process of small hydraulic cylinders from a knowledge retention perspective, developing a knowledge schema to identify and segregate explicit and tacit knowledge. The aim of the schema is to understand the relationship of various knowledge types in an engineering design context. Most of the knowledge identified in the design activities is explicit. The tacit element is concerned with knowing what theory to use and when to apply it.

Fei et $\mathrm{a}^{23}$ reported that design changes and their impacts are difficult to capture and evaluate, which make product design in uncertainty. They argued that design change propagation is caused by deign conflicts arising from the initial and consequent changes which are difficult to predict without knowing their preceding change solutions, since all the following changes are based on the solutions of preceding changes. Many design conflicts arising from change analysis can be tackled by reusing well-formalised and managed knowledge abstracted from previous design cases. They proposed a methodology for design change management to implement these ideas using modelling method, matrix analytical method and knowledge based engineering. ${ }^{24}$ A system engineering modelling method was used to capture dependency relationships in and between functions and components. A matrix-based analytical method helps to trace change propagations and identify design conflicts, behavioural and spatial connections between components. With the help of a knowledge repository and the reasoning method, designers are able to find proper solutions for design conflicts occurring in design change propagation.

A further investigation was carried out by Saunders et $\mathrm{al}^{4}$ with the collaborating multi-national automotive manufacturer, and their study confirmed that there is a distinct lack of integration between the numerous standalone web-based databases and ICT tools utilised within the company. The study also highlighted the inadequacy in the overall knowledge management infrastructure to effectively store new knowledge created during new vehicle development programs and make it widely accessible to support on-going product development later in the vehicle lifecycle during full-scale high-volume manufacture. The incorporation of the extended enterprise architecture, as the critical organisational factor missing in previous frameworks, will support the development of a more suitably optimised web-based knowledge management system. It is proposed that this will better serve the community of geographically dispersed engineering teams on global automotive systems engineering projects throughout the complete vehicle system lifecycle. 


\section{Manufacturing Knowledge Issues in Product Development}

Manufacturing knowledge was defined as knowledge about manufacturing processes, assembly, quality, materials handling and operation planning by Pahl and Beitz. ${ }^{25}$ Design engineers were encouraged to reduce risks as far as possible and also to 'design for manufacturing', and the manufacturing impact was seen primarily as a cost impact ${ }^{26}$. The Design for Manufacture and Assembly (DFMA) methodology originated by Boothroyd et $\mathrm{al}^{27}$ to enable greater consideration of manufacturing and assembly requirements before the detail design stage. The aim was to design products which are easier to manufacture and assemble which can consequently be produced at a lower cost. Process also needs to be considered in conjunction with the materials to be selected. ${ }^{28}$

A practical application of the DFM methodology is seen in O'Driscoll. ${ }^{29}$ With this application, a number of checkpoints were built into the existing design process to ensure that the required knowledge had been supplied. There were three stages of increasing detail, including definition, development and validation/scale up. Initial process list and process capabilities were considered in the definition stage. Chen $^{30}$ also acknowledged the influence of process, material and shape and looked at manufacturing feasibility and cost. For the earlier stages of product development, this was seen as a 'screening out' process for unsuitable processes. A conceptual framework for a manufacturing decision support system was developed, which was in essence about information interaction between designers and manufacturing engineers and its components.

In terms of content, manufacturing knowledge tends to be defined as method, capability and cost. The link between material, shape and process is strongly defined. The desired situation is that the manufacturing process is mature and stable in that it has a known capability that matches the product attributes. However, there is a recognition that such knowledge may be less detailed earlier in the design process, and this has not been defined specifically. ${ }^{11}$ Design knowledge and manufacturing knowledge have been noted as separated specialist domains with a need to share knowledge between them. As discussed earlier, the themes of knowledge sharing and the need to support this within a knowledge management environment are apparent. Engineering knowledge is viewed as being, or needing to be explicit. However, the support through tacit knowledge is also essential. ${ }^{31}$ The knowledge type and appropriate support systems should also be linked to the nature of product development and manufacturing processes.

Although new manufacturing processes have been acknowledged, the inherent nature of previous methodologies was to select capable processes to reduce risk. Innovative processes which are still in development and are therefore immature have not been considered by most previous researchers. Bohn discussed how processes are not inherently capable, particularly in high-tech industries. Further development 
work is required to develop or validate such processes to a capable standard. This stance was echoed by Grant and Gregory ${ }^{21}$ and Mountney et $\mathrm{al}^{32}$ in their study of the global transfer of manufacturing processes, noting that manufacturing processes will change over time according to their maturity.

Another important issue is how to manage manufacturing knowledge in the supply chain during collaborative product development. To produce products at the targeted cost, time, and quality, the supply chain must be aligned with product development processes and contribute to key decisions making. This will allow manufacturing firms to overcome problems such as (partially) failed product launches due to the lack of timely provision of parts and systems caused by insufficient capacities in the supply chain. ${ }^{33}$ With integrated product development and supply chain management, enterprises have the benefit of increased supply chain capability, thus increasing the effectiveness of new product introduction and improving their overall performance. They have tried to link the global product development process of a multi-national automotive manufacturer to its global network of suppliers ${ }^{34}$ at some selected key integration points through an integrated framework, and provided guidelines to identifying where critical decision are made in collaboration with the supply chain.

In the manufacturing lifecycle of aerospace products, large amounts of data are generated throughout the activities involved. Much of this data contains useful knowledge for engineers to improve various aspects of Design for Manufacturing (DFM) of new or existing products that may help reduce defects in future manufacturing activities. An investigation was carried out by El Souri, et al ${ }^{35}$ at a large UK based manufacturer of aerospace products that aim to introduce an improved approach that supports design engineering activities to make use of the 'data' generated to drive the number of re-occurring defects down. They collected raw data captured from defects on complex aerospace products, both manufactured in-house and by third party suppliers, and applied a structured approach, in order to evaluate its effectiveness towards the DFM knowledge that can be used to reduce re-occurring defects. ${ }^{36}$ The evaluation has been analysed which has shown that knowledge management can have a significant effect on DFM practice when the collected raw data from defects and associated processes are structured, represented and linked to an itemized bill of material (BOM) in a design engineering environment, and the main focus of their work was the capture of manufacturing knowledge related to defects of parts from suppliers.

\section{Information-System Approach to Manufacturing Knowledge Sharing}

The Information-System approach is concerned with the capture, representation, and re-use of knowledge, particularly applicable to situations where there is some degree of standardisation in processes. Successful knowledge sharing is at the heart of this approach from two perspectives. The main perspective is 
interoperability. In order for knowledge to be shared and successfully interpreted across different platforms, it must be defined and represented in a standardised manner. This requires the definition of knowledge exchange standards, protocols and languages, such as STEP, CORBA, UML and ontologies. The second perspective is concerned with the techniques used to define knowledge in a specific domain and interpret this knowledge from the point of view of other domains. Two techniques which are of particular interest are features and information models, as both have been used extensively to represent design and manufacturing engineering.

\subsection{Knowledge Sharing Using Features}

A Feature has been defined as attributes which sit above the pure geometry of a component to convey information which is of use in an engineering setting. ${ }^{37}$ Early research into features investigated their use in the design and manufacturing domains, primarily focusing on the detailed design stage of the product development process. As research progressed, the role of the feature expanded to other stages of the design process and other knowledge domains, such as manufacturing, assembly and tolerance specification. Consequently, the definition of a feature has also expanded to that of an information carrier to be used across the entire lifecycle of a product.

Two main techniques have been developed to exploit feature applications: feature-recognition (also called feature extraction) and feature-based (also known as design-by-features). In feature recognition, manufacturing features are extracted from geometric models. ${ }^{38}$ Research using this technique typically yields an automated numerical control and process plan generating system for manufacturing. With the feature-based approach, a number of pre-defined features are used to generate part models relatively quickly. ${ }^{39 \sim 43}$ Pre-defined engineering information can also be conveyed within the features and be evident right from the start of the design phase. The aim is to embed process capability in the product during the design phase. A third technique in features is feature conversion, also known as feature transformation or feature mapping. The technique is normally used to map features from one domain to another, and in multiple-feature view modelling, where a number of feature views relevant to particular domain activities can be created simultaneously.

In any systems developed to use features, a clear, structured hierarchal definition is required such as the taxonomies presented in reference ${ }^{44}$ and reference ${ }^{45}$. Information systems to support design and manufacturing analysis have been developed using the three feature techniques described above, at varying stages of the design process and for a number of applications. Information systems using features have been mainly concerned with the detail design stage. Then there was a move into using features for earlier stages of product development. Brunetti and Golob ${ }^{46}$ adapted features to concept design. They concentrated on modelling the functional behaviour of a product using a working principle model so that it can be directly linked to the product geometry 
generated later in the design process. Bradley and Maropoulos ${ }^{47}$ developed a product model by representing some overall dimensions but not detailed geometry for manufacturing and cost analysis at concept and embodiment design stages. Their developed system was called Concurrent Assembly and Process Assessment Blocks for Engineering manufacture (CAPABLE).

A major limitation in the expansion of features has been the ability to model and view more than one feature view at a time. Feature conversion, and the resulting technique of multiple feature-view modelling can be used to create features at different stages of the product cycle and map them across. ${ }^{48}$ The design view is accepted as the primary model view, with all model changes being driven through this view. An example of such a system can be seen in reference ${ }^{49}$ : an intermediate model created using a design-by-features approach is the hub of the system and provides a shared product model providing different independent self-contained subsets of the entire model depending on the required application. However, the feature transformation is one-way and if any updates are required, they need to be made via the primary model. De Kraker et $\mathrm{al}^{50}$ introduced a system as a means of addressing this issue. Their approach is to support all feature views simultaneously and to perform multiple feature conversions between these views. The approach adopted could be said to work the opposite way to the typical feature conversion approach.

The use of feature semantics (the meaning attributed to a feature for a specific stage of the product lifecycle) was explored by Bidarra and Bronsvoort. ${ }^{51}$ Their object-oriented approach created feature classes as structured descriptions of all the properties of a given feature type, known as semantics. The system was developed further to become a web-based collaborative feature modelling system for collaborative design including concept design, assembly design, detail design and manufacturing planning functions. ${ }^{52}$

Features have been used as information carrier between machining and inspection planning by $\mathrm{Li}^{\mathrm{et}} \mathrm{al}^{53}$. They reported an integrated system which feedback inspection data to adjust NC programs for machining. The highly innovative aspects of their research is the on-line adaptive manufacturing mechanism based on dynamic inspection data with associated changes made in NC coding recorded as knowledge. In another paper, they described a feature-based adaptive manufacturing planning system with a flexible NC programming method that dealt with changing resources such as availability of machines and tooling, unexpected job requirements and changes in production schedules. ${ }^{54}$ They have developed mechanisms in both the pre-processing and postprocessing modules of their implemented system. Li's work has been well recognised as the pioneering investigation in modelling the process knowledge in the whole manufacturing process (through dynamic features by their definition). They reported a novel principle that divides large free-form surfaces into sub- 
surfaces according to different optimisation criteria, especially individual requirements and available resources. ${ }^{55}$ Their method was based on rank-two tensor for tool path optimisation in terms of the machining efficiency of large size complex freeform surfaces.

\subsection{Knowledge Sharing Using Information Models}

One issue of feature technology is that in order to derive a feature it must already be based on some known geometry, therefore the design itself must have reached some stage of maturity in order for the feature to be derived. The success of this approach in early design must therefore be questioned. From a technical perspective, the number of feature views and their synchronisation would make an industrial application to a complex mechanical component prohibitive. An alternative method of sharing knowledge which is not so tied to geometry, yet still offers some standardised knowledge sharing is sought. Such a method can be found in information models.

Information models are a formal method of standardising, structuring and representing knowledge. Developed to improve interoperability, they are usually modelled using standard languages. They are an attractive option for modelling knowledge in the product development process because they are not closely tied to geometry as features. Geometric information can be included, and there is scope to include much wider sources of information. The work by a number of researchers has defined three types of information models for sharing design and manufacturing knowledge. These are the product model, the manufacturing model and the product range model.

A product model contains all the information specific to the design of the product, with different views to represent each function. ${ }^{56}$ A manufacturing model contains the information relating to the process capability and manufacturing resource availability. ${ }^{4}$ Manufacturing information can be categorised into how to produce a part or how to use the manufacturing facilities in an enterprise. A product range model provides a link between the product and manufacturing views, associating functional information with potential design solutions. ${ }^{57}$ Information is shared between the different viewpoints of the different models using a knowledge transformation layer. ${ }^{58}$

Information models are more flexible than features. However, the information they contain must be codifiable to be expressed in a standardised language. Knowledge classified as explicit could be processed by information systems, whilst tacit knowledge could not, except perhaps as a video clip. There are examples of successful manufacturing models that have been created for mature manufacturing processes. The most popular approach is to create a web-enabled system linking together either PLM or CAD systems using STEP for product data 
exchange and CORBA as a standard for object-oriented integration. Modelling languages such as EXPRESS (modelling language created for STEP), Smalltalk, UML and XML have been used for implementations. One question is whether to have a large system with 'one size fits all' functionality (similar to the off-the-shelf ERP packages) or whether to have a suite of tools which could be successfully integrated. Regarding interoperability, the challenge for the developers is to use the relevant model for each task, and to communicate the results in a suitable form to the various parties involved, whose needs are different and interests are diverse. ${ }^{59}$

There are also many examples of information systems to model manufacturing knowledge to support different stages of product development when available information is at different levels of completeness. Ordegoni and Cugini $^{60}$ developed a rule-based design support system to capture manufacturing process and rationale knowledge for re-use. The manufacturing constraint rules and parameters are mainly related to the selected shape and material of the component in product development. A knowledge management database was developed to support the manufacturing assessment of gas turbine engines. ${ }^{61}$ The database used a feature-based product model and an integrated process model. Specific operations from the process model were linked into the product model at component and feature levels. The database functionality includes the assessment of manufacturing processes, costs and capability.

$\mathrm{Zha}^{62}$ considered the selection of materials and manufacturing processes in a concurrent DFM environment. The focus was on the early stage of product development. Design requirements were categorised as material properties, form requirements and manufacturing requirements. They claimed that these categories could also be used for the categorisation of process requirements. Van der Laan and van Tooren ${ }^{63}$ proposed a method for automating the management of trade-offs during the early stage of design for aerospace components, particularly aimed at manufacturing analysis and costing. A specific manufacturing model view was also created with the aim of removing unfeasible manufacturing concepts at an early stage.

Manufacturing enterprises around the world have made significant efforts to provide high value-added services in addition to their traditional product development and manufacturing business. A product service system (PSS) was presented by Zhu et $\mathrm{al}^{60}$ aiming to better integrate product development with maintenance and service operations. Their project focused on the maintenance, repair and overhaul (MRO) in the aerospace industry. A product data model and a MRO service model were proposed and implemented. An ontology-based knowledge representation model was developed for the reuse of knowledge unambiguously in MRO services. An attempt was made to demonstrate the role of PSS in the aerospace industry as a decision support tool for MRO services. Product lifecycle management (PLM) environment and Web-based technologies were developed 
to enable the methodology to provide services and support in the aerospace manufacturing and flight operations business. $^{64}$

However, in the research area of product service systems and related computerized maintenance systems, there is a lack of investigation into the special nature, problems and requirements of high value machine tool maintenance, which are very important in modern digitized manufacturing systems. Wan et $\mathrm{al}^{65}$ investigated the various relationships between different stakeholders in the machine tools' lifecycle, focusing on knowledge management, communication and the decision-making processes. They explored the potential application of advanced content management systems in the manufacturing engineering domain which has been dominated by traditional engineering information systems. A prototype collaborative maintenance planning system was proposed, developed and evaluated using an example machine tool, ${ }^{66}$ which indicated that the content management technology has a number of advantages over the traditional engineering information systems (computer aided engineering, product data and lifecycle management, and enterprise resource planning systems) in managing machine tool maintenance and service information including dynamic and unstructured knowledge.

\subsection{Knowledge Reuse through the Design Reuse Approach}

Product family design is a proven method to provide product variety while maintaining production efficiency. However, its application has been restricted by the lack of relevant information. Design reuse is a promising approach to alleviate this difficulty. However, current design reuse practices, such as case-based reasoning, catalogue-based design and modular design, have only focused on one or a few aspects of product family design. A complete design reuse process model has not been defined.

A product family design reuse (PFDR) process model was developed ${ }^{6769}$ to accommodate the major issues of product family design. This model incorporates information modelling, information processing, and design synthesis and evaluation into a holistic model. Thus, it provides systematic support to build product platforms and design product families.

A multiple facet information model was developed to decompose existing product cases ${ }^{70}$. It can deal with heterogeneous product information with sufficient flexibility and representation rigor. A functional product architecture was established with the assistance of a new analytical tool, namely, the self-organizing map (SOM). Based on a formal presentation of the product functions, SOM can cluster the product functions without human supervision. In comparison to traditional methods that depend on manual operations or heuristic rules, the SOM method is fast and relies less on human intelligence. The SOM method, in combination with a few other knowledge extraction operations, enables a more efficient reuse of the product information. 


\section{Including Social Perspectives in Manufacturing Knowledge Sharing}

The business management sector of research has been critical of the Information-System approach to knowledge management. Information systems do not consider the social perspectives and the communication between people. ${ }^{71}$ The explicit and tacit elements of the knowledge are divorced. Walsham suggested that the Information-System approach misunderstands and misrepresents tacit knowledge. It is seen as something which can be converted into explicit knowledge and then stored, i.e., as a transferable object. Consequently, explicit knowledge has been promoted at the expense of instilling the meaning from tacit knowledge and such systems have ignored the need to manage knowledge simultaneously at both the explicit and tacit levels. Walsham suggested that such systems should be designed to promote the value of the sense reading and sense giving activities which would give them value, and suggested two methods - communities of practice within a shared boundary and organisational translators across domain boundaries.

Roberts $^{72}$ also examined the issue of knowledge transfer through the use of information and communication technologies (ICTs) and issues surrounding explicit and tacit knowledge transfer. Knowledge transfer is defined as the diffusion of knowledge from an individual to others. The knowledge transfer process is achieved by socialisation, education and learning which can either occur deliberately or as a by-product of another activity. Roberts noted that person-to-person (and preferably face-to-face) communication is the most critical element of technology transfer, and suggested that even video conferencing is insufficient for tacit knowledge transfer and trust building as the process of digitisation codifies the human element of the contact. Furthermore, initial tacit knowledge transfer is an essential pre-requisite for explicit knowledge transfer.

Johannessen et $\mathrm{al}^{73}$ noted that increasing investment in IT does not appear to have reaped the benefits, and were also concerned about the focus on explicit knowledge being to the detriment of tacit knowledge transfer. They were specifically concerned with the influence of tacit knowledge on the use of IT systems and vice versa. They saw the organisational challenge as being to transform personal tacit knowledge into organisational explicit knowledge. Processes for building trust and relationships are seen as being pivotal to this. Swan et al ${ }^{74}$ also acknowledged that IT-based knowledge management projects which focus primarily on codifying knowledge will not be able to deal with innovative (immature) knowledge. They view innovation as a timephased multi-function communication process, and therefore knowledge sharing is essential for this process and the development of new innovative approaches. They also share the stance that tacit knowledge cannot be codified because of its personal and context-specific elements. Consequently networking, a social 
communication process, was promoted as a major requirement of a successful process-based approach to innovation.

Mountney et $\mathrm{al}^{32}$ investigated the nature of manufacturing knowledge required for preliminary design and how this knowledge can be shared effectively between the specialist design and manufacturing domains. Their research was specifically concerned with immature innovative manufacturing knowledge for the preliminary design, when a lot of information about the product is still incomplete. A methodology was developed which support and consolidate the themes of tacit and explicit knowledge, codification and maturity of knowledge, and with an emphasis on the social knowledge sharing aspects and requirements needed in an industrial setting. Their methodology includes a process maturity audit to assess the manufacturing processes, and to establish the level of knowledge (completeness of information) required including process feasibility, capability and estimated cost.

Some researchers whose prime focus is the Information-System approach have attempted to recognise and address tacit knowledge requirements. Cheung et $\mathrm{al}^{75}$ acknowledged the necessity of tacit knowledge for knowledge sharing and seek to codify employee tacit knowledge and experience as part of 'know-how' in their latest development of an internet-based PDM system for collaborative product development. Koh and Gunasekaran ${ }^{76}$ reported work on managing uncertainty in manufacturing operation planning and scheduling was another demonstration of attempts to convert tacit knowledge to explicit knowledge.

Piorkowski et $\mathrm{al}^{77}$ investigated the importance of capturing knowledge during face-to-face meetings in the new product development process in the high value manufacturing sector. They described the concept of Dynamic Knowledge Management (KM) which is a combination of cultural and technological factors, including the cultural factors of people and their motivations, technological factors of content and infrastructure and, where these both come together, interface factors. In their paper, ${ }^{78}$ a dynamic knowledge management framework and tools was described for capturing and indexing face-to-face meetings. It was reported how the framework was discussed during a meeting of the collaborating company project stakeholders. Participants agreed the framework would have most benefit at the start of the product lifecycle before key decisions were made.

Evans et $\mathrm{al}^{79}$ reported a five-year participant-observation study at a largest aerospace and defence organisation, and proposed a virtual knowledge sharing framework in dispersed aerospace product development based on emergent social software platforms. As knowledge and social communications become increasingly important in modern engineering enterprises, emerging and fast developing social media technologies have 
shown significant potential in complementing traditional engineering information technologies for managing more dynamic and unstructured engineering information and knowledge. They demonstrated a new paradigm for collaboration and knowledge sharing during the product development process through the utilisation of emergent social software platforms including Web 2.0 technologies which have been increasingly and widely used for social communications and connectivity ${ }^{80}$ Compared with traditional engineering information systems, which are often highly complex and require specialized knowledge to maintain and operate, the new paradigm provides much simpler usability and less formal communication methods for employees.

The advent of Social Media in the last decade has changed the way many employees and global organisations communicate and interact with one another, providing a medium for information especially tacit knowledge to be transferred across the World Wide Web in a less formal (unstructured) manner. Zammit et al ${ }^{31}$ explored whether storytelling and video sharing functionality, embedded into a corporate social media site, were capable of facilitating the capture and sharing of employee knowledge during the product development cycle. They developed a knowledge capture and sharing framework which is directly driven by the knowledge users, addressing the special nature and application context of integrated design and testing operations. ${ }^{72}$ The use of social media, video sharing and storytelling technologies to capture complex engineering knowledge by the knowledge experts themselves, rather than by media professionals whom are paid to develop content.

\section{Summary and Recommendation for Future Research}

Knowledge management and sharing is critical to today's globalised product development, manufacturing and services. Information systems have been very successful in developing explicit, structured and standardised knowledge representations. The strength of the approach and hence focus of research is the ability to automate and therefore improve the efficiency of routine design, manufacturing planning and analyses tasks. The issue of interoperability is well recognised and is a prime focus of research activity. For this to be successful, the systems need to deal with 'known' knowledge, i.e., the design parameters are known and the manufacturing processes are mature. Conversely, knowledge which is immature, has some degree of being unknown and comes from people (tacit) is seen as undefined, unstructured, incomplete and unreliable. Therefore, the social and community approach to dealing with those knowledge, and systems developed by researchers more recently, have been reviewed. For future research and industrial application, both Information-System and Community approaches should be taken in real-life operations. In addition, the potential of the combined approach should be further explored to the management of other key issues such as the dynamics of knowledge, behavioural aspects, 
legacy data, changes in design and manufacturing, knowledge in global supply chain, the level of completeness, prioritisation of knowledge, the re-use knowledge, and big-data issues in engineering.

\section{Acknowledgements}

This paper includes introduction of some research projects carried out by previous $\mathrm{PhD}$ students supervised by the authors. The authors highly appreciate the $\mathrm{PhD}$ researchers' contribution to knowledge in the reviewed research topic. More information about these research projects can be found in the cited references.

\section{References}

1. Alavi M, Leidner D E. Knowledge Management and Knowledge Management Systems: Conceptual Foundations and Reserach Issues[J]. 2001. MIS Quarterly, 25(1), pp. 107-136

2. Evans R D, Gao J X, Martin N and Simmonds, C. A new paradigm for virtual knowledge sharing in product development based on emergent social software platforms[J]. Proceedings of the Institution of Mechanical Engineers Part B Journal of Engineering Manufacture, 2017.

3. Gao $\mathrm{J}$ and Bernard A, An overview of knowledge sharing in new product development, International Journal of Advanced Manufacturing Technology. doi: 10.1007/s00170-017-0140-5, 2017

4. Saunders T, Gao J X and Evans R D. Supporting global automotive product development projects through the integration of systems engineering knowledge, Proceedings of the $13^{\text {th }}$ International Conference on Manufacturing Research (ICMR2015), University of Bath, UK, 8-10 Sept 2015, p159-164.

5. Liu S and Young R I M. Utilizing information and knowledge models to support global manufacturing co-ordination decisions. International Journal of Computer Integrated Manufacturing, 2004,17(6), pp. 479-492.

6. Polanyi M. The Tacit Dimension[J]. 1966, 63(1):47-61.

7. Nonaka I. Nonaka, I.: A Dynamic Theory of Organizational Knowledge Creation. Organization Science 5(1), 14-37[J]. Organization Science, 1994, 5(1):14--37.

8. Zack M H. Managing Codified Knowledge[J]. Sloan Management Review, 1999, 40(4): pages. 45-58.

9. Hicks R C, Dattero R, Galup S D. A metaphor for knowledge management: explicit islands in a tacit sea[J]. Journal of Knowledge Management, 2007, 11(1):5-16.

10. Bohn R E. Measuring and Managing Technological Knowledge[J]. Sloan Management Review, 1994, 36(1):61.

11. Mountney S, Gao J. Manufacturing Knowledge Management: Requirements for Preliminary Design[C]// Conference on Leading the Web in Concurrent Engineering: Next Generation Concurrent Engineering. IOS Press, 2006:515-522.

12. Fahey L, Prusak L. The Eleven Deadliest Sins of Knowledge Management[J]. California Management Review, 1998, 40(3):265-276.

13. Tuomi I. Data Is More than Knowledge: Implications of the Reversed Knowledge Hierarchy for Knowledge Management and Organizational Memory[C]// Hawaii International Conference on System Sciences. IEEE Computer Society, 1999:1071. 
14. McMahon C, Lowe A, Culley S. Knowledge management in engineering design: personalization and codification[J]. Journal of Engineering Design, 2004, 15(4):307-325.

15. Saunders T, Gao J, Shah S. A case study to evaluate lean product development practices in the global automotive industry[J]. International Journal of Product Development, 2017, 19(5/6):307.

16. Giddaluru M P, Gao J X, Bhatti R. A Modular Product Structure Based Methodology for Seamless Information Flow in PLM System Implementation[J]. Computer-Aided Design and Applications, 2015, 12(6):742-752.

17. Giddaluru M P, Gao J X and Bhatti R. Integrating product knowledge with modular product structures in PLM, In: ICIDM2017: International Conference on Innovative Design and Manufacturing, 17-19 July 2017, Milan, Italy.

18. Hicks B J, Culley S J, Allen R D, et al. A framework for the requirements of capturing, storing and reusing information and knowledge in engineering design[J]. International Journal of Information Management, 2002, 22(4):263-280.

19. Chui Y P, Helander M G, Fu Q Y. Knowledge identification and management in product design[J]. Journal of Knowledge Management, 2006, 10(6):50-63.

20. Ferrari F M, Toledo J C D. Analyzing the knowledge management through the product development process[J]. Journal of Knowledge Management, 2013, 8(8):117-129.

21. Grant E B, Gregory M J. Tacit knowledge, the life cycle and international manufacturing transfer[J]. Technology Analysis \& Strategic Management, 1997, 9(2):149-162.

22. Wong W L P, Radcliffe D F. The tacit nature of design knowledge[J]. Technology Analysis \& Strategic Management, 2000, 12(4):493-512.

23. Fei G, Gao J, Owodunni D, et al. A Model-driven and Knowledge-based Methodology for Engineering Design Change Management[J]. Computer-Aided Design and Applications, 2011, 8(3):373-382.

24. Fei G Y, Gao J, Owodunni D, et al. A method for engineering design change analysis using system modelling and knowledge management techniques[J]. International Journal of Computer Integrated Manufacturing, 2011, 24(6):535551.

25. Pahl G, Beitz W, Feldhusen J, et al. Engineering Design: A Systematic Approach[J]. Students Quarterly Journal, 2010, 34(133):63-64.

26. El Souri M, Gao J, Owodunni O, Simmonds C and Martin N, A Structured Approach to Defect Data Management for Improving DFM Implementation in Aerospace Manufacturing, accepted by the International Journal of Product Lifecycle Management, Inderscience Enterprises, 1743-5129 (Online), 2017.

27. Boothroyd G, Dewhurst P and Knight, W. 2002a. Product Design for Manufacture and Assembly. 2nd edn. New York: Marcel Dekker, pp. v.

28. Boothroyd G, Dewhurst P and Knight, W. 2002b. Product Design for Manufacture and Assembly. 2nd edn. New York: Marcel Dekker, pp. 43.

29. O'Driscoll M. Design for manufacture. Journal of Materials Processing, 2002 , 125, pp. 318-321. 
30. Chen W J. Manufacturing information for engineering design.[J]. University of Cambridge, 1998.

31. Zammit J P, Gao J, Evans R. Development of a knowledge sharing framework for improving the testing processes in global product development[J]. International Journal of Product Lifecycle Management, 2016, 9(1):1-18.

32. Mountney S L, Gao J X, Wiseall S. A knowledge system to support manufacturing knowledge during preliminary design[J]. International Journal of Production Research, 2007, 45(7):1521-1537.

33. Hasan S, Shah S, Gao J. A collaboration framework to support decision making in new product development with the supply chain[J]. 2013.

34. Hasan S M, Gao J, Wasif M, et al. An Integrated Decision Making Framework for Automotive Product Development

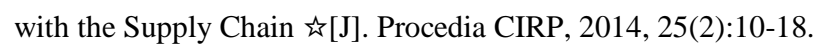

35. Souri M E. An Investigation into the Management of Design for Manufacturing Knowledge in an Aerospace Company[C]// International Conference on Manufacturing Research. 2016.

36. Souri M E. Improving Design for Manufacturing Implementation in Knowledge Intensive Collaborative Environments, An analysis of Organisational Factors in Aerospace Manufacturing[C]// International Conference of the IEEE Technology and Engineering Management Society. IEEE, 2017.

37. Parry-Banuck S. and Bowyer A. Feature Technology. 001/1993. University of Bath: University of Bath ,

38. Naish J C, Mill F G and Salmon J C. Implementation of process capability models to support computer aided process planning. Advances in Manufacturing Technology XI, 1997, pp. 375-379.

39. Gao J X, Tang Y S, Sharma R. A feature model editor and process planning system for sheet metal products[J]. Journal of Materials Processing Technology, 2000, 107(1-3):88-95.

40. Gayretli A, Abdalla H S. An object-oriented constraints-based system for concurrent product development[J]. Robotics and Computer-Integrated Manufacturing, 1999, 15(2):133-144.

41. Sharma R, Gao J X. A Progressive design and manufacturing evaluation system incorporating STEP AP224[J]. Computers in Industry, 2002, 47(2):155-167.

42. Li W D, Ong S K, Fuh J Y H, et al. Feature-based design in a distributed and collaborative environment[J]. ComputerAided Design, 2004, 36(9):775-797.

43. Ong S K, Li W D, Nee A Y C. STEP-based integration of feature recognition and design-by-feature for manufacturing applications in a concurrent engineering environment[J]. International Journal of Computer Applications in Technology, 2003, 18(1/2/3/4):ications in Technology.

44. Zha X F, Du H. A PDES/STEP-based model and system for concurrent integrated design and assembly planning[J]. Computer-Aided Design, 2002, 34(14):1087-1110.

45. Gindy N N Z. A hierarchical structure for form features[J]. International Journal of Production Research, 1989, 27(12):2089-2103. 
46. Brunetti G, Golob B. A feature-based approach towards an integrated product model including conceptual design information[J]. Computer-Aided Design, 2000, 32(14):877-887.

47. Bradley H D, Maropoulos P G. A Concurrent Engineering Support System for the Assessment of Manufacturing Options at Early Design Stages[M]// P

48. Bronsvoort W F, Jansen F W. Feature modelling and conversion: key concepts to concurrent engineering[M]. Elsevier Science Publishers B. V. 1993. Proceedings of the Thirty-First International Matador Conference. Macmillan Education UK, 1995.

49. Martinoa T D, Ingerb. Design and engineering process integration through a multiple view intermediate modeller in a distributed object-oriented system environment[J]. Computer-Aided Design, 1998, 30(6):437-452.

50. Kraker K J D, Dohmen M, Bronsvoort W F. Multiple-way feature conversion to support concurrent engineering[C]// ACM Symposium on Solid Modeling and Applications. ACM, 1995:105-114.

51. Bidarra R, Bronsvoort W F. Semantic feature modelling[J]. Computer-Aided Design, 2000, 32(3):201-225.

52. Bronsvoort W F, Noort A. Multiple-view feature modelling for integral product development[J]. Computer-Aided Design, 2004, 36(10):929-946.

53. Li Y, Wang W, Li H, Ding Y. Feedback method from inspection to process plan based on feature mapping for aircraft structural parts [J], Robotics and CIM, 28 (2012): 294-302.

54. Liu C, Li Y, Gao X. Feature-based adaptive numerical control programming method for the environment of changing manufacturing resources [J], Proc IMechE Part B: J of Manufacturing Manufacture. 2015, 13(5): 237-247.

55. Liu X, Li Y, Ma S, Lee CH. A tool path generation method for freeform surface machining by introducing the tensor property of machining strip width[J]. Computer-Aided Design, 2015, 66:1-13.

56. Canciglieri O J, Young R I M. Information sharing in Multiview point injection moulding design and manufacturing[J]. International Journal of Production Research, 2003, 41(7):1565-1586.

57. Costa C A, Young R I M. Product range models supporting design knowledge reuse[J]. 2001, 215(3):323-337.

58. Young B, Cutting-Decelle A F, Guerra D. Sharing Manufacturing Information and Knowledge in Design Decision and Support[M]// Advances in Integrated Design and Manufacturing in Mechanical Engineering. Springer Netherlands, 2003:173-185.

59. Wang H F, Zhang Y L. CAD/CAM integrated system in collaborative development environment[J]. Robotics and Computer-Integrated Manufacturing, 2002, 18(2):135-145.

60. Ordegoni M and Cugini U. Design and manufacturing knowledge management, Seventh International Conference on Manufacturing and Management (PCM 2002), 27-29 November 2002, PCMM pp476-481

61. Balogun O, Hawisa H, Tannock J. Knowledge management for manufacturing: the product and process database[J]. Journal of Manufacturing Technology Management, 2004, 15(7):575-584.

62. Zha X F. A web-based advisory system for process and material selection in concurrent product design for a manufacturing environment[J]. International Journal of Advanced Manufacturing Technology, 2005, 25(3-4):233-243. 
63. Van Der Laan A.H. and Van Tooren M.J.L. 2005. Manufacturability analysis of aircraft movables in a multidisciplinary design environment. First International Conference on Innovation and Integration in Aerospace Sciences.

64. Zhu H, Gao J, Cai Q. A product-service system using requirement analysis and knowledge management technologies[J]. Kybernetes, 2015, 44(5):823-842.

65. Wan S, Li D, Gao J. Exploring the Advantages of Content Management Systems for Managing Engineering Knowledge in Product-service Systems [C] The, International Conference on Digital Enterprise Technology - Intelligent Manufacturing in the Knowledge Economy Era. 2016:446-450.

66. Wan S, Li D, Gao J, et al. A collaborative machine tool maintenance planning system based on content management technologies[J]. International Journal of Advanced Manufacturing Technology, 2016

67. Xu Q L, Ong S K, Nee A Y C. Function-based design synthesis approach to design reuse[J]. Research in Engineering Design, 2006, 17(1):27-44.

68. Ong S K, Xu Q L, Nee A Y C. Design Reuse Methodology for Product Family Design[J]. CIRP Annals Manufacturing Technology, 2006, 55(1):161-164.

69. Q. L. Xu, S. K. Ong, A. Y. C. Nee. Evaluation of product performance in product family design re-use[J]. International Journal of Production Research, 2007, 45(18-19):4119-4141.

70. Ong S K, Xu Q L and Nee A Y C, "Design Reuse in Product Development Modelling, Analysis and Optimization”, World Scientific, Series on Manufacturing Systems and Technology - Vol.4, ISBN-10 981-283-262-9, 2008.

71. Walsham G. Knowledge Management: The Benefits and Limitations of Computer Systems[J]. European Management Journal, 2001, 19(6):599-608.

72. Roberts J. From Know-how to Show-how? Questioning the Role of Information and Communication Technologies in Knowledge Transfer[J]. Technology Analysis \& Strategic Management, 2000, 12(4):429-443.

73. Johannessen J A, Olaisen J, Olsen B. Mismanagement of tacit knowledge: the importance of tacit knowledge, the danger of information technology, and what to do about it[J]. International Journal of Information Management, 2001, 21(1):3-20.

74. Swan J, Newell S, Scarrough H and Hislop D. Knowledge management and innovation: Networks and networking. Journal of Knowledge Management, 1999, 3(4), pp. 262-275.

75. Cheung W M, Bramall D G, Maropoulos P G, et al. Organizational knowledge encapsulation and re-use in collaborative product development[J]. International Journal of Computer Integrated Manufacturing, 2006, 19(7):736750.

76. Koh S C L, Gunasekaran A. A knowledge management approach for managing uncertainty in manufacturing[J]. Industrial Management \& Data Systems, 2006, 106(4):439-459.

77. Piorkowski B, Gao J, Evans R. A Case-study: Finding References to Product Development Knowledge from Analysis of Face-to-Face Meetings[M]// Globalized Solutions for Sustainability in Manufacturing. Springer Berlin Heidelberg, 2011:564-568. 
78. Piorkowski B A, Gao J X, Evans R D, et al. A dynamic knowledge management framework for the high value manufacturing industry[J]. International Journal of Production Research, 2013, 51(7):2176-2185.

79. Evans R D, Gao J X, Martin N, et al. Exploring the benefits of using Enterprise 2.0 tools to facilitate collaboration during product development[J]. International Journal of Product Lifecycle Management, 2015, 8(3):233-252.

80. Zammit J, Gao J, Evans R, et al. A knowledge capturing and sharing framework for improving the testing processes in global product development using storytelling and video sharing[J]. Proceedings of the Institution of Mechanical Engineers Part B Journal of Engineering Manufacture, 2017(5):095440541769406. 